\title{
Hormones and the Stressed Brain
}

\author{
E. RONALD DE KLOET \\ Division of Medical Pharmacology, Leiden Amsterdam Center for Drug Research, \\ Leiden University Medical Center, Leiden University, Leiden, the Netherlands
}

\begin{abstract}
The stress system orchestrates brain and body responses to the environment. Cortisol (in humans) or corticosterone (in rodents) are important mediators of the stress system. Their action - in concert-is crucial for individual differences in coping with other individuals, which in turn depend on genetic- and experience-related factors. The actions exerted by cortisol and corticosterone have an enormous diversity. They include the regulation of rapid molecular aggregations, membrane processes, and gene transcription. In the latter transcriptional regulation, the corticosteroid hormones have two modes of operation. One mode is mediated by high-affinity mineralocorticoid receptors (MRs), which control gene networks underlying stabilization of neuronal activity as determinant for the sensitivity to trigger immediate responses to stress organized by corticotrophin-releasing hormone (CRH)-1 receptor. Whereas disturbance of homeostasis is prevented by MR-mediated processes, its recovery is facilitated via the low-affinity glucocorticoid receptors (GRs) that require stress levels of cortisol. GRs promote in coordination with CRH-2 receptors and the parasympathetic system behavioral adaptation and enhances storage of energy and information in preparation for future events. The balance in the two stress system modes is thought to be essential for cell homeostasis, mental performance, and health. Imbalance induced by genetic modification or stressors changes specific neural signaling pathways underlying cognition and emotion. This yin-yang concept in stress regulation is fundamental for genomic strategies to understand the mechanistic underpinning of corticosteroid-induced stress-related disorders such as severe forms of depression.
\end{abstract}

KEYWORDS: stress; behavior; brain; corticosteroids; receptors; genes

\section{INTRODUCTION}

A fundamental question in stress research is how stress system mediators such as the corticosteroid hormones can change their action from protection to damage. Current wisdom predicts that a healthy condition is a highly reactive system that readily turns on and off its responses to stressors. If the stress system responds slowly, or when stress reactions persist, its mediators enhance vulnerability to disease for which the individual is predisposed. For further progress in unraveling the mechanism, it is essential to understand how transient changes in expression of stress responsive gene products are converted to prolonged aberrant gene regulation that may result in maladaptive physiologic and behavioral changes. ${ }^{1}$

Address for correspondence: E. Ronald de Kloet, Ph.D., Division of Medical Pharmacology, LACDR/LUMC, Leiden University, PO Box 9502, 2300 RA Leiden, the Netherlands. Voice: +31-71-527.6210; fax: +31-71-527.4715.

e-mail: e.kloet@lacdr.leidenuniv.nl

Ann. N.Y. Acad. Sci. 1018: 1-15 (2004). (C) 2004 New York Academy of Sciences. doi: 10.1196/annals.1296.001 
The corticosteroid hormones operate in concert with catecholamines and other transmitters. If corticosteroid control is insufficient, stress reactions are too strong. ${ }^{2}$ Alternatively, if adaptation to stress fails, circulating corticosteroid levels remain elevated for a prolonged period of time. Too low and too high cortisol concentrations are damaging. Thus, excess corticosteroid has catabolic consequences and leads to breakdown of vital functions. ${ }^{3,4}$ At least $50 \%$ of depressed patients have a flattened circadian rhythm with elevated cortisol particularly during the diurnal trough in the face of sympathetic hyperactivity. ${ }^{5,6}$ These include the patients suffering from melancholic depression as opposed to the pathophysiologic mirror image; the atypical depressed patient shows signs and symptoms of hypocortisolemia. ${ }^{7}$ Hypercorticism is often a hallmark of severe depression with psychotic features. ${ }^{8}$ The psychotically depressed patient seems to respond favorably to antiglucocorticoid therapy, ${ }^{9}$ as has been reported for Cushing patients. ${ }^{10}$ If further validated, the finding represents the first pathophysiologic substrate of a psychiatric disorder caused by excess cortisol that can be rescued by antiglucocorticoids.

The initial question on the role of the stress system can be rephrased as: How does cortisol change its action from protective to harmful? What is the cause and what are the consequences? To address these questions, I first discuss briefly the action mechanism of the corticosteroids. These hormones act conditionally, and accordingly the context they operate is important. Second, a potential animal model for depression is discussed in which the stress system is dysregulated: mice genetically selected for extreme differences in coping style. Third, new strategies to identify novel molecular targets in stress circuitry for treatment of stress-related disorders are embedded in the section future directions. Most studies that have corticosterone as the principal naturally occurring glucocorticoid are in the mouse and rat, whereas humans have cortisol as the principal naturally occurring glucocorticoid.

\section{BRAIN CORTICOSTEROID RECEPTORS OPERATE IN BINARY FASHION}

McEwen et al. ${ }^{11}$ discovered corticosteroid receptors in the limbic brain, notably the hippocampus where corticosterone was retained in high amounts. The synthetic glucocorticoid dexamethasone labeled the pituitary corticotrophs and to some extent the corticotrophin-releasing hormone $(\mathrm{CRH})$ neurons in the paraventricular nucleus $(\mathrm{PVN}){ }^{12}$ Dexamethasone in tracer amounts poorly labeled the brain ${ }^{13}$ because multidrug resistance P-glycoprotein (mdr Pgp) and related proteins in the blood-brain barrier extrude the synthetic steroid. This was demonstrated by the tenfold higher accumulation of ${ }^{3} \mathrm{H}$-dexamethasone in the brain of Pgp knockout mice than in the wild types, and neurons of the hippocampus now weakly retain this steroid. ${ }^{3} \mathrm{H}$-cortisol, which does not occur naturally in the rat or mouse, is poorly retained in wild type brains and seems to be a Pgp substrate. In the Pgp mutants, profound labeling of hippocampal neurons occurs with cortisol, as is the case with corticosterone. Human MDR also recognizes cortisol rather than corticosterone as substrate, and liquid chromatography/mass spectrometry analysis of post-mortem human brain samples revealed that corticosterone is a relatively more preferred corticosteroid by the human brain than cortisol. ${ }^{14}$

Even in mdr mutants, dexamethasone does not label the limbic neurons as well as corticosterone and cortisol do. We discovered that although these steroids are glucocorticoids, dexamethasone binds as expected with high affinity to the glucocorticoid 
receptors (GRs), and corticosterone prefers with highest affinity the mineralocorticoid receptors (MRs) and has a tenfold lower affinity than dexamethasone to GR. ${ }^{15}$ Hence, in our original experiments corticosterone labeled the MR, and the tracer was too low in quantity to occupy the classical dexamethasone-labeled GR. This discovery was possible because of the synthesis of "pure" glucocorticoids and the cloning of GR and MR. ${ }^{16}$ The precise MR/GR topography was revealed in brain with immunocytochemistry and in situ hybridization, ${ }^{17-19}$ and with confocal microscopy the receptors appeared to be co-localized in neurons of the hippocampus, ${ }^{20}$ amygdala, and medial prefrontal cortex. ${ }^{21}$ Although this brain MR is chemically identical to kidney MR, the latter is aldosterone selective because of local intracellular metabolic conversion of the naturally occurring glucocorticoids cortisol and corticosterone. ${ }^{22,23}$

MR and GR bind to glucocorticoid response elements (GREs), but only GR is capable of interacting with transcription factors such as activating protein (AP-1) and nuclear factor $\kappa \mathrm{B}(\mathrm{NF} \kappa \mathrm{B}) .{ }^{24}$ This finding provided a firm mechanistic underpinning to the concept advanced by Tausk ${ }^{25}$ and Munck et al. ${ }^{26}$ that glucocorticoids block primary stress reactions. They achieve this blockade through interaction of the GR monomers with transcription factors driven by catecholamines and other transmitters. Recently, co-regulator molecules were identified that seemed to be powerful modulators of nuclear receptor function. ${ }^{27}$ Members of the steroid co-activator receptor family of proteins promote agonist-induced receptor activation by permitting recruitment of, for example, $\mathrm{CBP} / \mathrm{p} 300$ transcription activators. The co-repressor molecules promote repression of gene transcription. The GR antagonist mifepristone (RU 486) provides an example of the possible modes of interaction with steroid receptor signaling. The antagonist acts as antagonist at GREs only if sufficient corepressor is available (FIG. 1). In vitro transfection experiments suggest that variable stoichiometry of co-repressors and co-activators may underlie differential MR/GR functioning.

Recently, evidence was obtained that intracellular receptors also trigger cascades of molecular assembly (e.g., tubulin polymerization) ${ }^{28}$ Thus, for intracellular receptors previously thought to be involved only in gene regulation, rapid mechanisms are beginning to unfold.

\section{MR AND GR OPERATE IN THE ONSET AND TERMINATION OF THE STRESS RESPONSE}

\section{Cells}

On the cellular level, using the hippocampal slice revealed two general principles. ${ }^{29-33}$ First, the control exerted by MR or GR seemed to proceed in a U-shaped manner. Ion conductance and transmitter responses were maximal in the absence of corticosterone when no receptor was active and in the presence of high supraphysiologic concentrations of the steroid when both receptors were active. Intermediate corticosterone concentrations occupying predominantly MR and little GR that reflect the average steroid concentration during the day minimize the cell responses. Second, these responses form the mechanistic basis for phenomena on the network level, such as LTP, that also have been demonstrated to show a U-shaped dose responsive- 


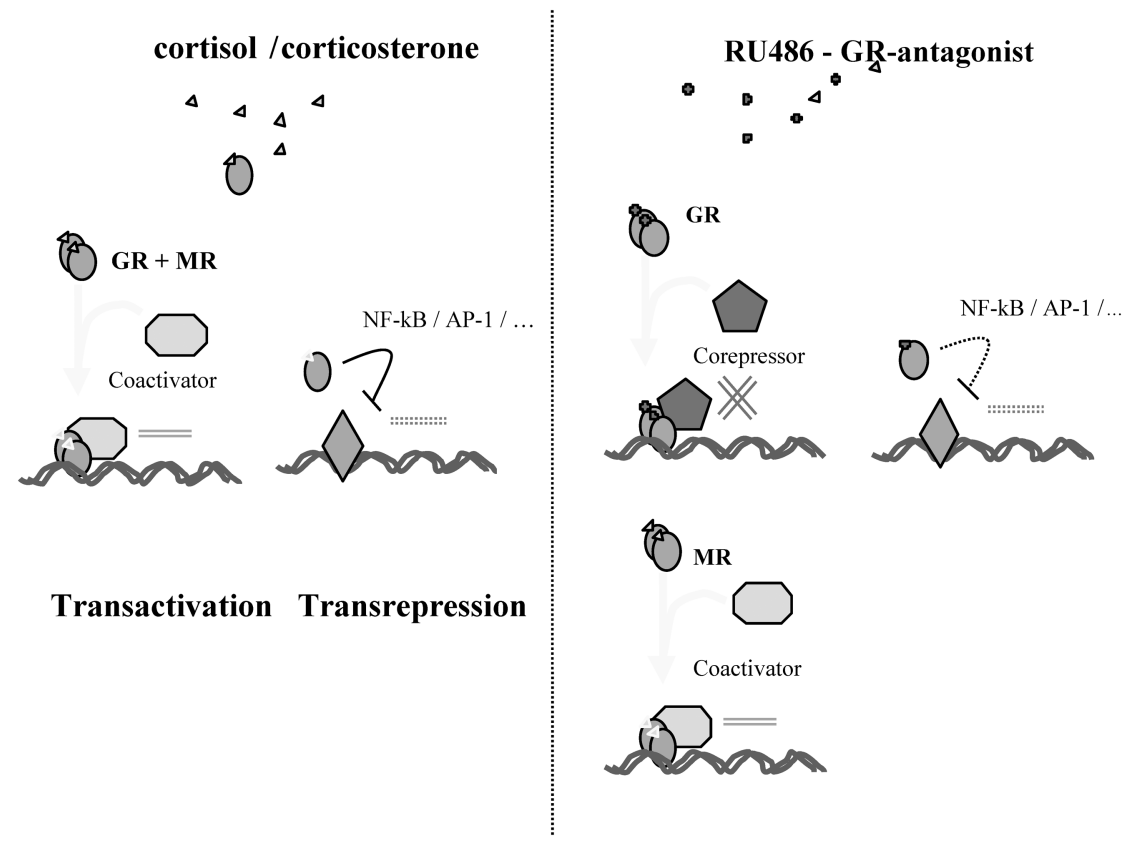

FIGURE 1. Action mechanism of corticosteroid hormones. Left: the naturally occurring glucocorticoid agonists cortisol and corticosterone interact with mineralocorticoid and glucocorticoid receptors (MR and GR), which upon dimerization recruit co-activators to stimulate gene transcription (transactivation). As monomers, GR, but not MR, can interfere with activation of gene transcription by transcription factors (NFKB/AP-1) triggered by membrane signalizations (transrepression). Right: GR dimerizes upon glucocorticoid antagonist RU 486 and recruits co-repressors for blockade of agonist-stimulated gene transcription. MR is not affected and escapes blockade, as does transrepression involving GR monomers and transcription factors. (Courtesy of Dr Onno Meijer.)

ness to corticosterone ${ }^{34}$ On a more generalized note, the cellular work demonstrates that MR stabilizes excitability on the cell and circuit level in the hippocampus, whereas GR suppresses excitability transiently raised by excitatory stimuli.

\section{Neuroendocrinology}

In neuroendocrine regulation, the intracerebral MR and GR blockade, using selective antagonists, exerts a profound and differential effect on measures of HPA activity. Adrenally intact animals were used in all experiments. The basis of our experiments was that we distinguished the blockade of GR in the HPA core (i.e., pituitary corticotrophs and PVN micro-environment) from blockade of MR or GR in stressor-specific afferents from brain stem, amygdala-locus coeruleus, prefrontal cortex, hippocampus, and other forebrain structures. The latter blockade interferes with processing of information and behavioral responses and leads to subsequent changes in HPA regulation. Thus, exposure to a novel environment was used as stressor because the limbic-cortical brain 
circuits involved in attention, appraisal, fear, and reward abundantly express MR and GR. The studies showed that the MR antagonist RU 28318 causes a rise in basal trough and peak levels of HPA activity and an enhanced response to the novelty stressor. ${ }^{35}$ This effect after central MR blockade was maintained after intrahippocampal administration. ${ }^{36}$ The GR antagonist mifepristone had no effect on basal trough activity because no GR is occupied under these conditions. Rather, GR blockade attenuated and prolonged the response to the novelty stressor. ${ }^{35}$ The attenuation of the novelty-induced response was mimicked with antagonist application in the dorsal hippocampus, and the prolonged response required GR blockade in the PVN. ${ }^{36-38}$

Upon continuous infusion of a few ng icv of mifepristone, after 4 days the amplitude of the circadian rhythm became more enhanced because the peak rather than the trough levels in HPA activity rose. ${ }^{39}$ This phenomenon could be an aspect of the beneficial therapeutic effect of mifepristone in psychotic depression. As is the case in the rat, chronic mifepristone enhanced the amplitude of the flattened circadian rhythm in cortisol characteristic for the disease (Schatzberg and Belanoff, unpublished observations).

There are three relevant notions based on current knowledge of the neuroendocrine system. First, there is a rich diversity in stressor-specific pathways activating the neurosecretory parvocellular CRH neurons of the PVN through predominant aminergic and GABAergic innervations. ${ }^{40,41}$ These pathways include (1) the ascending brain stem aminergic inputs thought to mediate "systemic" stressors and (2) the "processive" or "psychological" stressors requiring processing of information in higher brain structures. ${ }^{42}$ The latter inputs from limbic-cortical regions modulate a GABAergic interneuronal network in the PVN micro-environment, ${ }^{41,43}$ providing a stressor-specific neurochemical signature to the neurosecretory neurons. ${ }^{44}$

Second, the PVN integrates a diversity of signals that provide a neuroendocrine signature ${ }^{45}$ to exert control over adrenocortical activation by neuroendocrine and autonomic pathways. ${ }^{42}$ In the PVN CRH neurons, the stress-induced AP-1 pathway is blocked by corticosterone,${ }^{46}$ suggesting a powerful vasopressin link in the HPA core.

Third, the actions ${ }^{47}$ exerted by corticosterone on the brain have an enormous diversity. There are tonic actions mediated by MR- and GR-mediated actions that require the high corticosterone concentrations during the circadian peak and after stress. The latter corticosterone actions feed back on the same circuits that triggered their secretion (i.e., the CRH/VP neurons in the PVN and the afferents stemming from peripheral [metabolic, immune, inflammatory] and central [psychologic] sources).

Thus, corticosterone control depends on the phase of the CRH pulse generator, ${ }^{48}$ the nature and duration of the afferent stimulus, ${ }^{49}$ and the mechanism underlying the processing of stressful information. ${ }^{46,50}$ The inhibitory GABAergic network in the PVN microenvironment are corticosterone targets in their own right.

Given all these mutually interactive networks, it is difficult to sort out the contribution of corticosterone to tonic and feedback control in the HPA core versus each individual afferent pathway under the great variety of stressor-specific conditions.

\section{Behavior}

In the behavioral realm, central MR activation stimulates autonomic outflow, ${ }^{51}$ facilitates the conservation/withdrawal response if animals are exposed to a severe stressor, ${ }^{52}$ and enhances aggressive behavior of a resident mouse to an intruder. ${ }^{53}$ In 


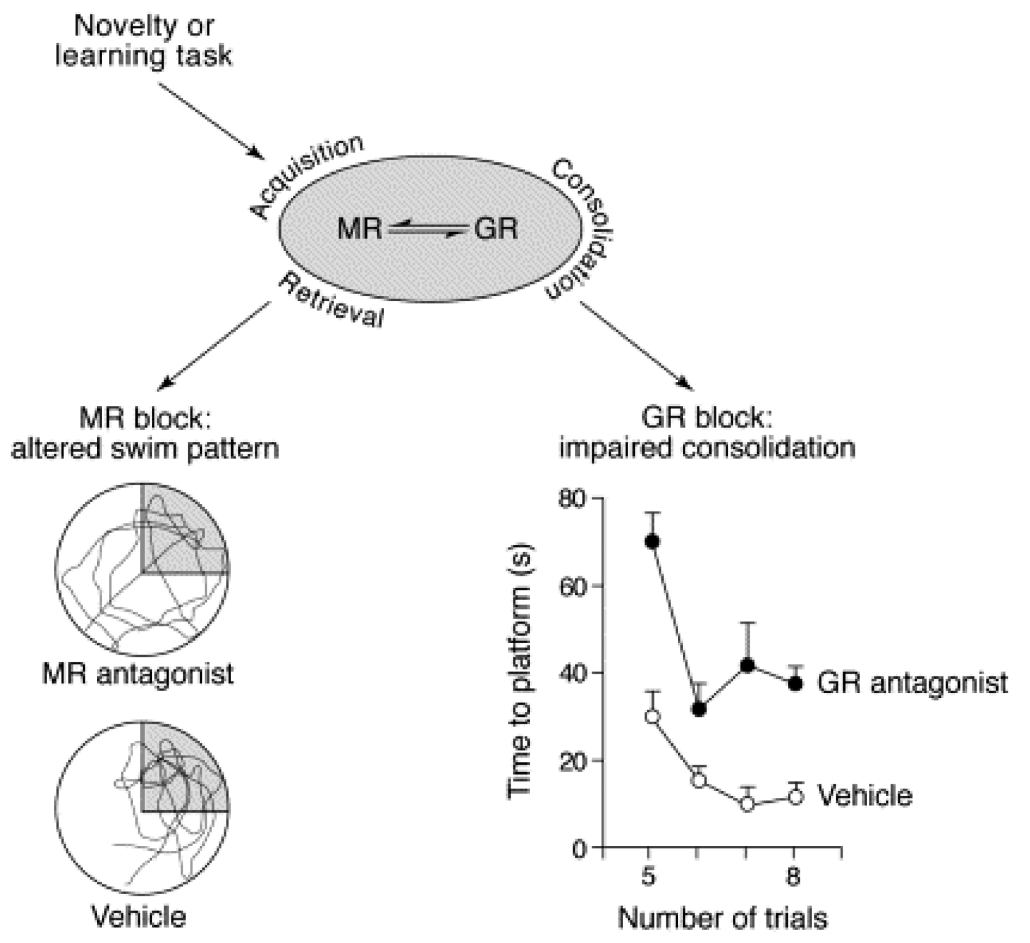

FIGURE 2. MR and GR affect different aspects of information processing. After exposure to a learning task, MR blockade 30 to $45 \mathrm{~min}$ before retrieval on day 2 changed the swim pattern. Inhibition of GR immediately after acquisition on day 1 results in impaired performance $24 \mathrm{~h}$ later. These MR- and GR-mediated effects on information processing facilitate behavioral adaptation. ${ }^{57}$

the spatial learning tests, MR affects interpretation of environmental information and selection of the appropriate behavioral response to deal with the challenge. Experimental evidence for this thesis comes from the administration of a few ng mineralocorticoid antagonist icv immediately before testing, which altered the behavioral pattern in a maze in search for a route to escape or to find food that the animal had learned to locate the previous day ${ }^{54}$ (FIG. 2). The neural mechanism underlying the latter MR-mediated action is not known; nor is it known how the autonomous, neuroendocrine, and behavioral consequences of central MR blockade mutually affect each other.

Blockade of brain GR impairs the storage of new information. ${ }^{55-57}$ A glucocorticoid antagonist administered around the time of learning in the hippocampus or in the amygdala ${ }^{58,59}$ impaired the consolidation of newly acquired information. As a consequence, 24 hours later, the rat was unable to retrieve the information that was learned the previous day and had to learn the maze problem again. Likewise, mutant mice with a point mutation in GR, which obliterates binding to DNA, are unable to 
store learned information. ${ }^{60}$ This suggests that corticosteroid-induced cognitive performance requires transactivation, as was previously found in the cellular responses to corticosterone in hippocampus ${ }^{61}$ because such mutants lack the direct activation of GREs but have a GR that can interact with other transcription factors. ${ }^{62}$ Transgenic mice with downregulated GRs (knockdown) show cognitive defects and elevated plasma ACTH and corticosterone concentrations in response to stress.

If corticosterone or stressors are administered before retrieval, the animal switches to a more opportune response while eliminating the irrelevant learned behavior. Mice exposed to chronic stress and high corticosterone concentrations deteriorate in spatial learning, whereas the reverse occurs after chronic treatment with GR antagonists. The chronic GR blockade in brain seems to enhance cognitive performance. ${ }^{63}$

\section{MR AND GR OPERATE IN TWO STRESS SYSTEM MODES}

The key CNS systems generating the stress response have two modes of operation that involve two families of CRH-related peptides ${ }^{64,65}$ (TABLE 1). One mode involves the fast, CRH-driven, neuroendocrine/sympathetic "fight-flight" response mediated by CRH-1 receptors. This fast responding system includes $\mathrm{CRH}$-producing neurons located in the PVN, the amygdala, the noradrenergic neurons located in the locus coeruleus, and other aminergic cells in the brain stem. In the periphery, the adrenal cortex producing cortisol and the adrenal medulla secreting catecholamines, particularly adrenalin, are the principal pacemakers.

The other slower system promotes recovery and adaptation and seems to be activated by the recently discovered urocortins acting via CRH-2 receptors. ${ }^{66,67}$ The urocortin II (stresscopin-related) and urocortin III (stresscopin) peptides have a distinctly different localization from $\mathrm{CRH}$ and were identified as selective ligands for the $\mathrm{CRH}-2$ receptor system. ${ }^{66,68}$ Urocortin I is synthesized in a discrete region in the midbrain, the Eddinger Westphal nucleus, and binds to both CRH receptor sites. Urocortin II is expressed in PVN and locus coeruleus and urocortin III in the hypothalamic area rostral of the PVN, the preoptic nucleus, and medial amygdala but not in cere-

TABLE 1. Modes of stress adaptation

\begin{tabular}{ll}
\hline Mineralocorticoid Receptors & Glucocorticoid Receptors \\
\hline Corticotrophin-releasing hormone (CRH) & Stresscopin \\
CRH-1 receptor & CRH-2 receptor \\
Sympathetic & Parasympathetic \\
Immediate & Late sustained \\
Fight/fight & Coping \\
\hline
\end{tabular}

NotE: $\mathrm{CRH}-1$ and $\mathrm{CRH}-2$ receptor systems drive the immediate response mode and the late adaptive mode of the stress system. ${ }^{66}$ MR determines the threshold or sensitivity of the fast response; GR represents the slow adaptive mode that terminates the fast response and that prepares for the future through storage of energy and information. 
bellum, cerebral cortex, or pituitary. Their terminal fields innervate hypothalamic and brain stem areas matching CRH-2 receptor distribution. ${ }^{69}$

Administration of the urocortins II and III evokes anxiolytic responses as opposed to the anxiogenic depression-like behavior and hypersensitivity evoked by CRH. ${ }^{66}$ Some phenomena after CRH are also observed in animal models of depression (e.g., decreased food intake, inhibition of sexual behavior, sleep disturbances, and psychomotor activation). Opposing actions are being recorded for the urocortins II and III, and this has led some researchers ${ }^{66}$ to suggest that $\mathrm{CRH}$ and urocortin are anti-parallel stress systems that function as organizers of the sympathetic and parasympathetic response, respectively. These data strongly suggest a role of imbalance in the CRH/ urocortin family of peptides in the pathophysiology of states of anxiety and depression.

\section{Synthesis}

How are the corticosteroids implicated? The cellular data in various limbic regions suggest that MR prevents the disturbance of homeostasis, whereas GR promotes its recovery. On the physiological and behavioral levels, this implies that MR is implicated in a mechanism determining the threshold or sensitivity of the CRHCRH-1 receptor-driven stress system response. Through GR, the stress-induced activation in the various modalities of stress system afferents and in the hypothalamicpituitary $\mathrm{CRH} / \mathrm{POMC}$ core of the system are facilitated in termination. In this way, GR is assumed to act synergistically to the late responding urocortin II/III-CRH-2 system promoting recovery and adaptation (TABLE 2).

We postulate that the balance in these stress systems is important for maintenance of health and homeostasis. ${ }^{47}$ FIGURE 3 depicts this stress system balance idea in its stable (homeostasis) and labile ${ }^{70}$ versions. It implies that, in the case of imbalance, the mediators act disproportionate. As a consequence, homeostatic control mechanisms are threatened, and the individual loses the ability to maintain homeostasis if challenged by an adverse event. This may lead to a condition of neuroendocrine dysregulation and impaired behavioral adaptation as a risk factor for the precipitation of depression. ${ }^{6,64}$ It is in this arena that the conversion of good versus bad corticosteroid effect occurs. If coping with stress fails, corticosteroids fail to terminate the stress reactions, and targets are exposed to elevated corticosteroid concentrations for a prolonged period of time. The state of hypercorticism is thought to sustain positive reverberating feedback loops that further aggravate the condition of stress system imbalance. The next sections describe an animal model generated by "nature-nurture"

TABLE 2. Function of mineralocorticoid receptors and glucocorticoid receptors on the cellular, neuroendocrine, and behavioral level ${ }^{47,57}$

\begin{tabular}{ll}
\hline Mineralocorticoid Receptors (type 1) & \multicolumn{1}{c}{ Glucocorticoid Receptors (type 2) } \\
\hline Limit disturbance of cellular homeostasis & Facilitate recovery of cellular homeostasis \\
$\begin{array}{l}\text { Control sensitivity of the stress-response } \\
\text { system }\end{array}$ & Restrain stress-induced responses \\
$\begin{array}{l}\text { Help to select appropriate behavioral } \\
\text { response }\end{array}$ & Promote information storage and adaptation \\
\end{tabular}




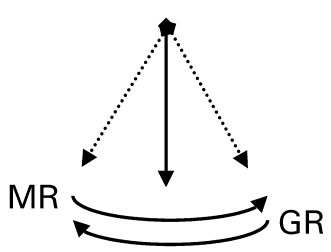

STABLE

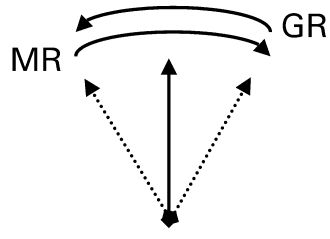

LABILE

FIGURE 3. MR- and GR-mediated effects as indices for stress system activity. Stable (homeostasis) and labile representations.

inputs that may be instrumental to dissect further the signaling pathways involved in this imbalance.

\section{ANIMAL MODEL}

Stress system responses display a large inter-individual variation in a normal population. In males, the extremes display an active fight/flight or a passive/conservation withdrawal response to a psychosocial challenge. Active animals rely on stable living conditions, show impaired adaptation to changing environment, display territorial aggression, and flee after defeat. Their sympathetic response pattern dominates. Passive animals thrive better on changing conditions and seem to be more dominated by parasympathetic activity and have high circulating cortisol levels after stress. Mouse and rat lines have been selected that represent these extremes in stress system activity. ${ }^{71,72}$ Female social interaction patterns have not been studied in these lines.

In the research of the late professor Bohus, male wild house mice were selected for long and short latency before attack of the intruder in the home territory. This selection also accumulated many of the traits characteristic for active and passive coping styles. The Short Attack Latency (SAL) mice display an innate active coping style toward environmental challenges with high stress-induced sympathetic and low adrenocortical activity. The Long Attack Latency (LAL) mice show a passive coping style and higher stress-induced corticosterone level. The SAL and LAL mice differ in many other parameters. For instance, the 5HT1A receptor expression and responsiveness in hippocampal CA1 neurons is more than $30 \%$ lower in LAL than in SAL. ${ }^{73,74}$ Landgraf et al..$^{71}$ have selected rat lines based on emotional responses, and these line differences could be eliminated with a V1A antagonist. This finding supports the evidence that in males vasopressin is also involved in genetic differences underlying anxiety and aggression (e.g., fight-or-flight responses). In females, oxytocin is more prominent in coping with a psychologic stressor. Oxytocin promotes aspects of social behavior, which led some researchers to the formulation of a tend-to-be-friend concept. ${ }^{75}$

These extremes selected for aggressive and emotional behavioral traits may represent individuals in which either the CRH-1 or CRH-2 stress system mode dominates. In Veenema's studies, ${ }^{73,74}$ basal hippocampal MR and GR and hypothalamic CRH 
expression were not different. In subsequent experiments, the LAL mice were repeatedly exposed to defeat or to the threat of defeat for 25 days. It seemed that the threat of defeat (i.e., LAL living next-door to the SAL in sensory but not physical contact) generated some of the features demonstrated in patients suffering from depression, notably an enhanced adrenocortical output and a lower MR/GR ratio. Hence, the passive behavioral coping style combined with low hippocampal 5HT1Areceptor function and elevated circulating corticosterone levels predicts to some extent enhanced stressor susceptibility. These measures, if further validated, may match in male mice the criteria for an animal model for depression. Whether the same reasoning holds for female mice remains to be seen because of their different coping style (i.e., the formation of female-female social bonds involving estrogens and oxytocin rather than the sympathetic fight-or-flight response of males that was the basis for the SAL versus LAL selection).

\section{FUTURE DIRECTIONS}

This article is based on the thesis that the stress system operates in an immediate fast responding and a slower adaptive mode in which the balance in brain corticosteroid receptor-mediated actions is one of the control nodes. This balance can be viewed as the set-point of the stress system in maintaining stabile or labile equilibrium in life processes. The stress mediators as beneficial or damaging agents can be determined from aspects of synaptic plasticity and from the rate of neurogenesis and neurodegeneration.$^{57,76-78}$ Selye $^{3}$ advocated the opposing actions of mineralocorticoid and glucocorticoid hormones and took as criterion their pro- and anti-inflammatory effects, respectively. Our work has given a central position to MR and GR mediating the action of one single hormone: corticosterone. The data suggest that MR-mediated actions are directed to maintain homeostasis and health, whereas GR promotes their recovery. There are three new developments with particular bearing for the field of stress hormones.

\section{Genetics of the Corticosteroid Receptor System}

In the coming years, SNPs may be identified in the corticosteroid-MR/GR transcription machinery that bias corticosteroid control of the stress response causing local imbalances in homeostatic control. ${ }^{79,80}$ Evidence for this was found in the rats selected for low- and high-anxiety behavior because one of the lines carried a vasopressin polymorphism. 81

An array of stress-responsive genes has been identified. ${ }^{82,83}$ These genes need to be analyzed in detail to answer questions such as how, where, and when they are expressed in stress-induced signaling pathways and, foremost, what their precise function is. ${ }^{1}$ Recently, in a hippocampal transcriptome, SAGE and GeneChip analysis showed under basal conditions a higher expression of several cytoskeleton genes in LAL (the passive copers) hippocampi than in SAL (active copers) and higher expression of a number of calmodulin-related genes and genes encoding components of a MAPK-cascade. This differential regulation of a raf/ERK pathway may be related to structural differences in hippocampus of LAL and SAL mice. A growth-arrest-specific gene (gas5) was the only downregulated gene in the LAL mice. ${ }^{84}$ These altered gene 
patterns can be postulated as markers for predisposition for stress-related disorders in comparison with patterns that become expressed during pathogenesis.

\section{Animal Models}

Behavioral tasks in which the analysis of simultaneous emotional and cognitive processes is combined with neurophysiologic network analysis may lead to better animal models. This may open up questions on the mode of action of stress hormones in control of cognitive processes leading to the precipitation of emotional disturbances characteristic of depression. In this respect, a distinction should be made between (1) the core of the HPA axis with emphasis on dysregulations in the PVN and its microenvironment in the organization of the stress response and (2) dysregulations in specific afferent stress inputs to the PVN (e.g., from medial prefrontal cortex, hippocampus, amygdala, and brain stem) that are also targets for the stress hormones. This is important because a novel generation of drugs may arise from targeting pathway nodes in central stress-regulation centers to treat stress-related brain disorders and their metabolic, cardiovascular, and neurodegenerative consequences. The potential success of the GR antagonists in the treatment of severe depression ${ }^{9}$ hints that the therapeutic focus on stress circuitry may be a rewarding approach.

\section{ACKNOWLEDGMENTS}

The financial support of the Netherlands Organization for Scientific Research (NWO) and the European Union is gratefully acknowledged. I thank Dr. Onno C. Meijer for critically reading this manuscript and dedicate this article to my long-time friend the late professor Béla Bohus, who has always been a big supporter of the Smolenice Castle Conference. The editorial assistance of Ellen M. Heidema is gratefully acknowledged.

\section{REFERENCES}

1. SabBan, E.L. \& R. KVETŇAnskÝ. 2001. Stress-triggered activation of gene expression in catecholaminergic systems: dynamics of transcriptional events. Trends Neurosci. 24: $91-98$.

2. Heim, C., U. Ehlert \& D.H. Hellhammer. 2000. The potential role of hypocortisolism in the pathophysiology of stress-related bodily disorders. Psychoneuroendocrinology 25: 1-35.

3. Selye, H. 1952. The Story of the Adaptation Syndrome. Acta, Montreal.

4. SAPOLSKY, R.M., L.M. ROMERO \& A.U. MUNCK. 2000. How do glucocorticoids influence stress responses? Integrating permissive, suppressive, stimulatory, and preparative actions. Endocr. Rev. 21: 55-89.

5. Belanoff, J.K., M. Kalehzan, B. Sund, et al. 2001. Cortisol activity and cognitive changes in psychotic major depression. Am. J. Psych. 158: 1612-1616.

6. Holsboer, F. 2001. Stress, hypercortisolism and corticosteroid receptors in depression: implications for therapy. J. Affect. Disorders 62: 77-91.

7. Gold, P.W. \& G.P. Chrousos. 1999. The endocrinology of melancholic and atypical depression: relation to neurocircuitry and somatic consequences. Proc. Assoc. Am. Physicians 111: 22-34.

8. Schatzberg, A.F., A.J. Rothschild, P.J. Langlais, et al. 1985. A corticosteroid/ dopamine hypothesis for psychotic depression and related states. J. Psychiatr. Res. 19: $57-64$. 
9. Belanoff, J.K., A.J. Rothschild, F. Cassidy, et al. 2002. An open label trial of C-1073 (mifepristone) for psychotic major depression. Biol. Psych. 52: 386-392.

10. VAN DeR Lely, A.J., K. FoeKen, R.C. VAN DeR MASt, et al. 1991. Rapid reversal of acute psychosis in the Cushing syndrome with the cortisol-receptor antagonist mifepristone (RU 486). Ann. Intern. Med. 114: 143-144.

11. McEwen, B.S., J.M. Weiss \& L.S. Schwartz. 1968. Selective retention of corticosterone by limbic structures in rat brain. Nature 220: 911-912.

12. De Kloet, E.R., G. Wallach \& B.S. McEwen. 1975. Difference in binding of corticosterone and dexamethasone to rat brain and pituitary. Endocrinology 96: 598-609.

13. Meijer, O.C., E.C.M. De LANGe, D.D. Breimer, et al. 1998. Penetration of dexamethasone into brain glucocorticoid targets is enhanced in mdr1 A P-glycoprotein knockout mice. Endocrinology 139: 1789-1793.

14. Karssen, A.M., O.C. Meijer, I.C. van der Sandt, et al. 2001. Multidrug resistance P-glycoprotein hampers the access of cortisol but not of corticosterone to mouse and human brain. Endocrinology 142: 2686-2694.

15. Reul, J.M. \& E.R. DE KLOET. 1985. Two receptor systems for corticosterone in rat brain: microdistribution and differential occupation. Endocrinology 117: 2505-2511.

16. Evans, R.M. \& J.L. ARRIZA. 1989. A molecular framework for the actions of glucocorticoid hormones in the nervous system. Neuron 2: 1105-1112.

17. FuXe, K., A.C. Wikström, S. ÖKret, et al. 1985. Mapping of glucocorticoid receptor immunoreactive neurons in the rat tel- and diencephalon using a monoclonal antibody against rat liver glucocorticoid receptor. Endocrinology 117: 1803-1812.

18. VAN EEKElen, J.A., W. JiANG, E.R. DE KlOET, et al. 1988. Distribution of the mineralocorticoid and the glucocorticoid receptor mRNAs in the rat hippocampus. J. Neurosci. Res. 21: 88-94.

19. Ito, T., N. MoRita, M. Nishi, et al. 2000. In vitro and in vivo immunocytochemistry for the distribution of mineralocorticoid receptor with the use of specific antibody. Neurosci. Res. 37: 173-182.

20. Van Steensel, B., E.P. van Binnendijk, C.D. Hornsby, et al. 1996. Partial colocalization of glucocorticoid and mineralocorticoid receptors in discrete compartments in nuclei of rat hippocampus neurons. J. Cell. Sci. 109: 787-792.

21. Helm, K.A., J.S. HAN \& M. Gallagher. 2002. Effects of cholinergic lesions produced by infusions of $192 \mathrm{IgG}$-saporin on glucocorticoid receptor mRNA expression in hippocampus and medial prefrontal cortex of the rat. Neuroscience 115: 765-774.

22. Edwards, C.R.W., P.M. Stewart, D. Burt, et al. 1988. Localisation of 11ß-hydroxysteroid dehydrogenase-tissue specific protector of the mineralocorticoid receptor. Lancet 2: 986-989.

23. SeCKL, J.R., J. YAU \& M. Holmes. 2002. 11Beta-hydroxysteroid dehydrogenases: a novel control of glucocorticoid action in the brain. Endocr. Res. 28: 701-707.

24. Auphan, N., J.A. DiDonato, C. Rosette, et al. 1995. Immunosuppression by glucocorticoids: inhibition of NF-kappaB activity through induction of I kappa B synthesis. Science 270: 286-290.

25. TAusK, M. 1951. Das Hormon: Hat die Nebenniere tatsächlich eine Verteidigungsfunktion? Vol. 3. Organon International BV, Oss, the Netherlands.

26. MuncK, A., P.M. GuYRe \& N.J. HolbrooK. 1984. Physiological functions of glucocorticoids in stress and their relation to pharmacological actions. Endocr. Rev. 5: 25-44.

27. MEIJER, O.C. 2002. Coregulator proteins and corticosteroid action in the brain. J. Neuroendocrinol. 14: 499-505.

28. BAULIEU, E.E. 2000. "New" active steroids and an unforeseen mechanism of action. C. R. Acad. Sci. III 323: 513-518.

29. JoËLS, M. \& E.R. DE KLOET. 1989. Effects of glucocorticoids and norepinephrine on the excitability in the hippocampus. Science 245: 1502-1505.

30. Jö̈LS, M. \& E.R. DE KLOET. 1992. Control of neuronal excitability by corticosteroid hormones. Trends Neurosci. 15: 25-30.

31. JoËLS, M. \& E.R. DE KLOET. 1994. Mineralocorticoid and glucocorticoid receptors in the brain: Implications for ion permeability and transmitter systems. Prog. Neurobiol. 43: 1-36. 
32. JoËLs, M. 1997. Steroid hormones and excitability in the mammalian brain. Front. Neuroendocrinol. 18: $2-48$.

33. JoËLS, M. 2001. Corticosteroid actions in the hippocampus. J. Neuroendocrinol. 13: 657-669.

34. Diamond, D.M., M.C. Bennett, K.E. Stevens, et al. 1990. Exposure to a novel environment interferes with the induction of hippocampal primed burst potentiation in the behaving rat. Psychobiology 18: 273-286.

35. Ratka, A., W. Sutanto, M. Bloemers, et al. 1989. On the role of brain mineralocorticoid (type I) and glucocorticoid (type II) receptors in neuroendocrine regulation. Neuroendocrinology 50: 117-123.

36. Van Haarst, A.D., M.S. Oitzl \& E.R. DE Kloet. 1997. Facilitation of feedback inhibition through blockade of glucocorticoid receptors in the hippocampus. Neurochem. Res. 22: 1323-1328.

37. DE KLOET, E.R., S. DE Kock, V. SchiLd, et al. 1988. Antiglucocorticoid RU 38486 attenuates retention of a behaviour and disinhibits the hypothalamo-pituitary-adrenal axis at different brain sites. Neuroendocrinology 47: 109-115.

38. Oitzl, M.S., A.D. van HaArst, W. Sutanto, et al. 1995. Corticosterone, brain mineralocorticoid receptors (MRs) and the activity of the hypothalamic-pituitaryadrenal (HPA) axis: the Lewis rat as an example of increased central MR capacity and a hyporesponsive HPA axis. Psychoneuroendocrinology 20: 655-675.

39. Van HaARST, A.D., M.S. Oitzl, J.O. Workel, et al. 1996. Chronic brain glucocorticoid receptor blockade enhances the rise in circadian and stress-induced pituitaryadrenal activity. Endocrinology 137: 4935-4943.

40. Palkovits, M. 1999. Interconnections between the neuroendocrine hypothalamus and the central autonomic system. Front. Neuroendocrinol. 20: 270-295.

41. Cole, R.L. \& P.E. SAWChEnKo. 2002. Neurotransmitter regulation of cellular activation and neuropeptide gene expression in the paraventricular nucleus of the hypothalamus. J. Neurosci. 22: 959-969.

42. Herman, J.P., W.E. Cullinan, D.R. Ziegler, et al. 2002. Role of paraventricular microenvironment in stress integration. Eur. J. Neurosci. 16: 381-385.

43. Herman, J.P. \& W.E. Cullinan. 1997. Neurocircuitry of stress: central control of the hypothalamo-pituitary-adrenocortical axis. Trends Neurosci. 20: 78-84.

44. PACAK, K. \& M. Palkovits. 2001. Stressor specificity of central neuroenodcrine responses: implications for stress-related disorders. Endocr. Rev. 22: 502-548.

45. Romero, L.M. \& R.M. SAPOLSKY. 1996. Patterns of ACTH secretagog secretion in response to psychological stimuli. J. Neuroendocrinol. 8: 243-258.

46. Kovács, K.J., A. Foldes \& P.E. SAwChEnKo. 2000. Glucocorticoid negative feedback selectively targets vasopressin transcription in parvocellular neurons. J. Neurosci. 15: $3843-3852$.

47. De Kloet, E.R., E. VReugdenhil, M.S. Oitzl, et al. 1998. Brain corticosteroid receptor balance in health and disease. Endocr. Rev. 19: 269-301.

48. Windle, R.J., S.A. Wood, S.L. Lightman, et al. 1998. The pulsatile characteristics of the hypothalamo-pituitary-adrenal activity ion Lewis and Fisher 344 rats and its relationship to different stress responses. Endocrinology 139: 4044-4052.

49. Laugero, K.D., M.E. Bell, S. Bhatnagar, et al. 2001. Sucrose ingestion normalizes central expression of corticotrophin releasing factor messenger ribonucleic acid and energy balance in adrenalectomized rats: a glucocorticoid-metabolic-brain axis? Endocrinology 142: 2796-2804.

50. Akana, S.F., A. Chu, L. Soriana, et al. 2001. Corticosterone exerts site specific and state dependent effects in prefrontal cortex and amygdala on regulation of adrenocorticotropic hormone, insulin and fat depots. J. Neuroendocr. 13: 625-637.

51. VAN DEN BuUSe, M., S.A. VAN ACKeR, M.F. FlutTERT, et al. 2002. Involvement of corticosterone in cardiovascular responses to an open-field novelty stressor in freely moving rats. Physiol. Behav. 75: 207-215.

52. Korte, S.M. 2001. Corticosteroids in relation to fear, anxiety and psychopathology. Neurosci. Biobehav. Rev. 25: 117-142.

53. HAller, J., S. Millar, J. VAN DE SChraAF, et al. 2000. The active phase-related increase in corticosterone and aggression are linked. J. Neuroendocrinol. 12: 431-436. 
54. Oitzl, M.S., M. Fluttert \& E.R. De Kloet. 1994. The effect of corticosterone on reactivity to spatial novelty is mediated by central mineralocorticosteroid receptors. Eur. J. Neurosci. 6: 1072-1079.

55. Oitzl, M.S. \& E.R. DE KLOET. 1992. Selective corticosteroid antagonists modulate specific aspects of spatial orientation learning. Behav. Neurosci. 106: 62-71.

56. Sandi, C., M. Loscertales \& C. Guaza. 1997. Experience-dependent facilitating effect of corticosterone on spatial memory formation in the water maze. Eur. J. Neurosci. 9: 637-642.

57. DE KlOET, E.R., M.S. OITZL \& M. JoËLS. 1999. Stress and cognition: are corticosteroids good or bad guys? Trends Neurosci. 22: 422-426.

58. RoozendaAl, B. 2000. 1999-Curt P. Richter Award. Glucocorticoids and the regulation of memory consolidation. Psychoneuroendocrinology 25: 213-238.

59. McGaugh, J.L. \& B. RoozendaAl. 2002. Role of adrenal stress hormones in forming lasting memories in the brain. Curr. Opin. Neurobiol. 12: 205-210.

60. Oitzl, M.S., H.M. Reichardt, M. JoËLS, et al. 2001. Point mutation in the mouse glucocorticoid receptor preventing DNA binding impairs spatial memory. Proc. Natl. Acad. Sci. USA 98: 12790-12795.

61. Karst, H., Y.J. Karten, H.M. Reichardt, et al. 2000. Corticosteroid actions in hippocampus require DNA binding of glucocorticoid receptor homodimers. Nat. Neurosci. 3: 977-978.

62. Reichardt, H.M., F. Tronche, S. Berger, et al. 2000. New insights into glucocorticoid and mineralocorticoid signaling: lessons from gene targeting. Adv. Pharmacol. 47: $1-21$.

63. Oitzl, M.S., M. Fluttert, W. Sutanto, et al. 1998. Continuous blockade of brain glucocorticoid receptors facilitates spatial learning and memory in rats. Eur. J. Neurosci. 10: 3759-3766.

64. Holsboer, F. 2003. Corticotropin-releasing hormone modulators and depression. Curr. Opin. Invest. Drugs 4: 46-50.

65. Hauger, R.L., D.E. Grigoriadis, M.F. Dallman, et al. 2003. International Union of Pharmacology. XXXVI. Current status of the nomenclature for receptors for corticotropin releasing factor and their ligands. Pharmacol. Rev. 55: 21-26.

66. HsU, S.Y. \& A.J. HsUEH. 2001. Human stresscopin and stresscopin-related peptide are selective ligands for the type 2 corticotropin-releasing hormone receptor. Nat. Med. 7: 605-611.

67. Reul, J.M. \& F. Holsboer. 2002. Corticotropin-releasing factor receptors 1 and 2 in anxiety and depression. Curr. Opin. Pharmacol. 2: 23-33.

68. Lewis, K., C. Li, M.H. Perrin, et al. 2001. Identification of urocortin III, an additional member of the corticotropin releasing factor (CRF) family with high affinity for the CRH 2 receptor. Proc. Natl. Acad. Sci. USA 8: 7570-7575.

69. Li, C., J. VAughan, P.E. SAWCHECKo, et al. 2002. Urocortin III-immunoreactive projections in rat brain: partial overlap with sites of type 2 corticotropin-releasing factor receptor expression. J. Neurosci. 22: 991-1001.

70. McEwEn, B.S. \& J.C. WingField. 2003. The concept of allostasis in biology and biomedicine. Horm. Behav. 43: 2-15.

71. LANDGRAF, R. \& A. Wigger. 2002. High vs low anxiety-related behaviour in rats: an animal model of extremes in trait anxiety. Behav. Genet. 32: 301-314.

72. Bohus, B., R.F. Benus, D.S. FoKKema, et al. 1987. Neuroendocrine states and behavioural and physiological stress responses. Progr. Brain Res. 72: 57-70.

73. Veenema, A.H., O.C. Meijer, E.R. DE Kloet, et al. 2003. Differences in basal and stress-induced HPA regulation of wild house mice selected for high and low aggression. Horm. Behav. 43: 197-204.

74. Veenema, A.H., O.C. Meijer, E.R. De Kloet, et al. 2003. Genetic selection for coping style predicts stressor susceptibility. J. Neuroendocrinol. 12: 256-267.

75. CARTER, C.S. 1998. Neuroendocrine perspectives on social attachment and love. Psychoneuroendocrinolgy 23: 779-818.

76. McEwen, B.S. 2002. Protective and damaging effects of stress mediators: the good and bad sides of the response to stress. J. Clin. Endocr. Metab. 51: 2-4.

77. SAPOLSKY, R.M. 2000. Glucocorticoids and hippocampal atrophy in neuropsychiatric disorders. Arch. Gen. Psych. 57: 925-935. 
78. Czeh, B., T. Michaelis, T. Watanabe, et al. 2001. Stress-induced changes in cerebral metabolites, hippocampal volume, and cell proliferation are prevented by antidepressant treatment with tianeptine. Proc. Natl. Acad. Sci. USA 98: 12796-12801.

79. DE RIJK, R.H., M.J. SchaAF, G. TURner, et al. 2001. A human glucocorticoid receptor gene variant that increases the stability of the glucocorticoid receptor beta-isoform mRNA is associated with rheumatoid arthritis. J. Rheumatol. 28: 2383-2388.

80. van Rossum, E.F., J.W. KoPer, N.A. HuIzenga, et al. 2002. A polymorphism in the glucocorticoid receptor gene, which decreases sensitivity to glucocorticoids in vivo, is associated with low insulin and cholesterol levels. Diabetes 51: 3128-3134.

81. LANDGRAF, R.M. \& A. WigGer. 2003. Born to be anxious: neuroendocrine and genetic correlates of trait anxiety in HAB rats. Stress 6: 111-119.

82. Datson, N.A., J. VAN DER PeRK, E.R. DE Kloet, et al. 2001. Identification of corticosteroid-responsive genes in rat hippocampus using serial analysis of gene expression. Eur. J. Neurosci. 14: 675-689.

83. FeldKer, D.E.M., N.A. Datson, A.H. Veenema, et al. 2003. Serial analysis of gene expression predicts structural differences in hippocampus of long attack latency and short attack latency mice. Eur. J. Neurosci. 17: 379-387.

84. FeldKer, D.E.M., N.A. DAtson, A.H. VeEnema, et al. 2004. Gene chips analysis of hippocampal gene expression profiles of short and long attack legacy mice: technical and biological implications. J. Neurosci. Res. 74: 701-716. 